\title{
Kinetics and Thermodynamic Studies of Adsorption of Methylene Blue from Aqueous Solutions onto Paliurus spina-christi Mill. Frutis and Seeds
}

\author{
Nilüfer Çiriğ Selçuk ${ }^{1}$ Şenol Kubilay ${ }^{2}$, Ali Savran², Ali Rıza Kul ${ }^{2}$ \\ ${ }^{1}$ Biology Department, Science Faculty, Yuzuncu Yil University, Turkey \\ ${ }^{2}$ Chemistry Department, Science Faculty, Yuzuncu Yil University, Turkey
}

\begin{abstract}
In the present study, Paliurus spina-christi Mill. Frutis and Seeds (PSCFS) was used as an adsorbent for the investigation of the adsorption kinetics and thermodynamic parameters of methyleneblue (MB) from aqueous solution at various temperatures and concentrations. Six kinetic models, the pseudo-first-order, pseudo-second-order, intra-particle diffusion, Elovich, Bangham and Avrami equations were used to predict the adsorption rate constants. It was found that the kinetics of the adsorption of MB onto PSCFS at different operating conditions was the best described by the pseudo-second-order model. The rate parameters of the other kinetic models for adsorption were also evaluated and compared to identify the adsorption mechanisms. The equilibrium constants were used to calculate thermodynamic parameters, such as the change of free energy, enthalpy and entropy. Thermodynamic analysis showed that adsorption was favourable and spontaneous, endothermic physical adsorption and increased disorder and randomness at the solid-solution interface of $M B$ onto PSCFS.
\end{abstract}

Keywords: Adsorption, Thermodynamic, Kinetic, Plant, Raw material

\section{Introduction}

Dye removal from wastewater is a topic of great interest in water pollution which is a serious environmental damage. Methylene blue is the most soluble dye in water in general used for printing cotton and tannin, dyeig leather, antiseptic and medical purposes [1]. Cationic dyes like methlene blue (MB) are more toxic than anionic dyes [2]. Although this dye does not harm people very much, it can cause irritation to the eyes and the skin [3]. MB may cause vomiting, nausea, diarrhea, profuse sweating, mental confusion, and gastritis and it can make breathing difficult [4]. Therefore, it has been focused on the removal of this dye from the wastewater. Numerous methods such as reverse osmosis, ion exchange, membrane filtration, conventional coagulation, chemical precipitation, and adsorption have been generally used to remove dyes from wastewater $[5,6]$. Of the removal methods, adsorption is one that sees increasing interest due to its potential efficiency, low energy consumption, high selectivity at molecular level, easy operation, and ability to separate various chemical compounds [7, 8]. Adsorption is a physical-chemical treatment of wastewater in which the dissolved molecule is attached to an adsorbent surface by means of physical and chemical properties. Depending on the nature of the adsorbent and the origin of the dyes, different interactions may be performed, such as electrostatic interaction and Van der Waals forces [9]. One of the important parameters in the adsorption process is the cost of the adsorbent. For this reason, it is important to use low cost adsorbents. Industrial by-products and agricultural waste products form important low-cost sources of adsorbent material. In recent years, a large number of lowcost adsorbents have been used to remove water from waste water such as cucumber peels [10], meranti sawdust[11], bagasse [12], durian leaf powder[13], watermelon seed hulls [10], grape pulp [14], chitosan [15], kenaf core fibers [16], hazelnut Shell [17], Delonix regia plant leaf [18], etc. However, no adsorption process has been reported on the use of PSCFS as adsorbent for the removal of cationic dye (MB) from water solution. In this study, an inexpensive natural adsorbent, PCSFS, was used to remove from the aqueous solution of MB. Contact time, initial concentration, initial $\mathrm{pH}$ and temperature effect on MB adsorption were investigated. In this article, kinetic and thermodynamic parameters were determined using available parameters.

\section{Materials and methods}

\subsection{Adsorbent}

PSCFS were collected from of Manyas region Balıkesir city, Turkey. The samples were washed several times with distilled water to remove impurity such as sand and dirt, and then dried in an oven at $55{ }^{\circ} \mathrm{C}$ for $24 \mathrm{~h}$. Dried samples were cut into pieces and then ground by using a crusher. The powder were passed through sieves and particles were collected under $0.06 \mathrm{~mm}$. These samples were used as adsorbent for adsorption experiments. 


\subsection{Adsorbate and other chemicals}

The basic cationic dye, MB, was used as the adsorbate in this study. The formula of methylene blue is $\mathrm{C}_{6} \mathrm{H}_{18} \mathrm{~N}_{3} \mathrm{SCl} .3 \mathrm{H}_{2} \mathrm{O}$, and moleculer weight $319.85 \mathrm{~g}$. The chemical structure of this dye is shown in Fig. 1. This dye was taken from Merck and used without any purification. The stock dye solution was prepared by dissolving $1 \mathrm{~g}$ of methylene blue in $1000 \mathrm{ml}$ distilled water. The solutions used at adsorption process were obtained by diluting the stock dye solution with deionised water to give the appropriate concentration of the solutions.

The T80+ UV/VIS spectrophotometer was used to determine the concentration of MB in solution at a maximum absorption wavelength of $660 \mathrm{~nm}$. A calibration curve was plotted between absorbance and certain concentrations of dye solution. Unknown MB concentration was measured using calibration curve.

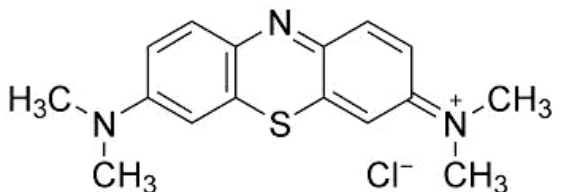

Fig. 1. Chemical structure of methylene blue

\subsection{Adsorption experiment}

Adsorption measurement was determined by batch experiments of known amount of the adsorbent with $1000 \mathrm{ml}$ of aqueous methylene blue solutions of known concentration in a series of $250 \mathrm{ml}$ conical flasks. The effect of the contact time on the amount dye adsorbed were investigated at different initial concentration of dye $(20,30,40$ and $50 \mathrm{mg} / \mathrm{L})$ at different temperatures $(298 \mathrm{~K}, 308 \mathrm{~K}$ and $318 \mathrm{~K}) .4 \mathrm{~g}$ PSCFS were added to 1 liter of dye solutions prepared at certain concentrations, natural $\mathrm{pH}$ and desired temperatures at $150 \mathrm{rpm}$ for specific time intervals. The concentration of dye remaining in solution without adsorption was determined by UV spectrophotometer using calibration curve. Adsorption experiments were made considering natural solution $\mathrm{pH}$, contact time, initial methylene blue dye concentration and temperature for adsorption kinetic and thermodynamic study. The amount of dye adsorbed onto PSCFS at time $t$ is $\mathrm{q}_{\mathrm{t}}$ (milligrams per gram) which was calculated by the following mass balance equation:

$$
q_{t}=\frac{\left(C_{o}-C_{t}\right)}{m} V
$$

Where $\mathrm{C}_{\mathrm{o}}$ is the initial dye concentration (milligrams per liter), $\mathrm{C}_{\mathrm{t}}$ is the concentration of dye at any time $\mathrm{t}, \mathrm{V}$ is the volume of solution (liters), and $\mathrm{m}$ is the mass of adsorbent in grams.

\section{Theory}

Kinetic models are used to check experimental data from the adsorption of MB onto PSCFS. The kinetics of dyes adsorption onto PSCFS are important to select the best test conditions for the adsorption process with the batch technique. The kinetic parameters, which are useful for the prediction of adsorption rate, give important information for designing and modeling the adsorption processes. In this study, the kinetics of MB onto PSCFS was analyzed using pseudo-first order, pseudo-second order, intra-particle diffusion, Elovich, Bangham and Avrami kinetic models.

\subsection{Pseudo-first order model}

Lagergren's kinetics equation may have been the first one in describing the adsorption of liquid-solid systems based on solid capacity. In order to distinguish kinetics equation based on concentration of solution and adsorption capacity of solid, Lagergren's first order rate equation has been called pseudo-first order[ 19]. The linear form of the pseudo-first order model is given as:

$$
\log \left(q_{m}-q_{t}\right)=\log q_{m}-\frac{k_{1} t}{2.303}
$$

Where $\mathrm{q}_{\mathrm{m}}$ and $\mathrm{q}_{\mathrm{t}}(\mathrm{mg} / \mathrm{g})$ are the adsorption capacities at equilibrium and at time $\mathrm{t}$ respectively. $\mathrm{k}_{1}\left(\mathrm{~min}^{-1}\right)$ is the rate constant of pseudo-first order adsorption. In order to obtain the constants of this model, the straight line plots of $\log \left(\mathrm{q}_{\mathrm{m}}-\mathrm{q}_{\mathrm{t}}\right)$ against $\mathrm{t}$ are drawn. The constants determined from the slope and intercept of the plot. 


\subsection{Pseudo-second order model}

The linear form of this model based on adsorption capacity is given as[19]:

$$
\frac{t}{q_{t}}=\frac{1}{k_{2} q_{m}^{2}}+\frac{1}{q_{m}} t
$$

and

$$
h=k_{2} q_{m}^{2}
$$

Where $\mathrm{k}_{2}$ is the rate of sorption ( $\left.\mathrm{g} / \mathrm{mg} \min \right), \mathrm{q}_{\mathrm{m}}$ the amount of adsorbate adsorbed onto adsorbent at equilibrium $(\mathrm{mg} / \mathrm{g}), \quad \mathrm{q}_{\mathrm{t}}$ is the amount of dye adsorbed at any time $(\mathrm{mg} / \mathrm{g})$ and $\mathrm{h}$ is the initial sorption rate $(\mathrm{mg} / \mathrm{g} \mathrm{min})$. The plot of $\mathrm{t} / \mathrm{qt}$ versus $\mathrm{t}$ shows a linear relationship. Values of $\mathrm{k}_{2}$ and equilibrium adsorption capacity $\mathrm{q}_{\mathrm{e}}$ were calculated from the intercept and slope of the plot of t/qt versus t according to Eq. 2.

\subsection{Intraparticle diffusion model}

In intraparticle diffusion model, the adsorbate transportation from the solution phase to the surface of the adsorbent particles occurs in several steps. All adsorption processes can be controlled by one or more steps, e.g., film or external diffusion, pore diffusion, surface diffusion and adsorption on the pore surface, or a combination of more than one step. The linear form of the intraparticle equation as follow:

$$
q_{t}=k_{i} t^{1 / 2}+C
$$

where $\mathrm{C}$ is the intercept and $\mathrm{k}_{\mathrm{i}}$ is the intra-particle diffusion rate constant $\left(\mathrm{mg} / \mathrm{g} \mathrm{min}^{1 / 2}\right)$. When intraparticle diffusion alone is the rate limiting step, then the plot of $\mathrm{q}_{\mathrm{t}}$ versus $\mathrm{t}^{1 / 2}$ passes through the origin [20]. When film diffusion is also taking place then the intercept is $\mathrm{C}$, which gives the idea on the thickness of the boundary layer.

\subsection{Elovich kinetic model}

Elovich equation is also used successfully to describe second order kinetic assuming that the actual solid surfaces are energetically heterogeneous, but the equation does not propose any definite mechanism for adsorbate-adsorbent [21]. It has extensively been accepted that the chemisorption process can be described by this semi-empirical equation [22]. The linear form of this equation is given by :

$$
q_{t}=\frac{\ln \left(a_{E} b_{E}\right)}{b_{E}}+\frac{1}{b_{E}} \ln t
$$

Where $a_{E}$ is the initial adsorption rate $(\mathrm{mg} / \mathrm{g} \mathrm{min})$, and the parameter $b_{E}$ is related to the extent of surface coverage and activation energy for chemisorption $(\mathrm{g} / \mathrm{mg})$. The Elovich coefficients could be computed from the plots qt versus $\ln t$. The initial adsorption rate $\left(\mathrm{a}_{\mathrm{E}}\right)$ and the desorption constant $\left(\mathrm{b}_{\mathrm{E}}\right)$ were calculated from the intercept and slope of the straight-line plots of qt against $\ln \mathrm{t}$.

\subsection{Bangham kinetic model}

Bangham's equation was used to evaluate whether the adsorption is pore-diffusion controlled. Bangham's plot should be linear if intraparticle diffusion is the only rate controlling step [23]. Non-linearity of the Bangham plots as well as the significant intercept values obtained from the intraparticle diffusion model indicated that both film diffusion as well as pore diffusion were rate-limiting [24].

$$
\log \log \left(\frac{C_{o}}{C_{o}-q_{t} M}\right)=\log \left(\frac{k_{B} M}{2.303 V}\right)+b \log t
$$

Where $\mathrm{C}_{0}$ is initial concentration $(\mathrm{mg} / \mathrm{L}), \mathrm{V}$ is volume of the solution $(\mathrm{mL}), \mathrm{M}$ is weight of the adsorbent $(\mathrm{g} / \mathrm{L})$, $\mathrm{q}_{\mathrm{t}}$ is amount of adsorbate retained at time $\mathrm{t}(\mathrm{mg} / \mathrm{g})$ and $\mathrm{b}, \mathrm{k}_{\mathrm{B}}$ are constants.

\subsection{Avrami kinetic model}

The Avrami kinetic equation determines some kinetic parameters, as possible changes of the adsorption rates in function of the initial concentration and the adsorption time, as well as the determination of fractionary kinetic orders [25]. The linearized form of Avrami equation is shown as follows:

$$
\ln \left[\ln \left(\frac{q_{m}}{q_{m}-q_{t}}\right)\right]=n_{A v} \ln k_{A v}+n_{A v} \ln t
$$

Where $\mathrm{k}_{\mathrm{Av}}$ is the Avrami adsorption kinetic constant and $\mathrm{n}_{\mathrm{Av}}$ is another constant, which is related to the adsorption mechanism changes. The slopes and intersections values of this equation provide the $\mathrm{n}_{\mathrm{Av}}$ and $\ln \mathrm{k}_{\mathrm{Av}}$ values, respectively. $\mathrm{n}_{\mathrm{Av}}$ value can be used to verify possible interactions of the adsorption mechanisms in relation to the contact time and the temperature. 


\section{Thermodynamic parameters}

Thermodynamic investigation is required to determine whether the adsorption process is favorable. The thermodynamic parameters, namely free energy $\left(\Delta \mathrm{G}^{\circ}\right)$, enthalpy $\left(\Delta \mathrm{H}^{\circ}\right)$, and entropy $\left(\Delta \mathrm{S}^{\circ}\right)$ have an important function to determine heat change the adsorption process for dye and PSCFS. These parameters is calculated by the following equations:

$$
\begin{gathered}
K_{e}=\frac{C_{A d s}}{C_{e}} \\
\ln K_{e}=\frac{\Delta S^{o}}{R}-\frac{\Delta H^{o}}{R T} \\
\Delta G^{o}=\Delta H^{o}-T \Delta S^{o}
\end{gathered}
$$

where, $\mathrm{K}_{\mathrm{e}}$ is the euilibrium constant, $\mathrm{C}_{\mathrm{Ads}}$ is the amount of dye adsorbed mg on the PSCFS per $\mathrm{dm}^{3}$ of the solution at equilibrium, adsorbentof adsorbent per unit liter of solution and $\mathrm{C}_{\mathrm{e}}$ is the equilibrium concentration of dye in the solution (milligrams per liter). $\mathrm{R}$ is the universal gas constant $(8.314 \mathrm{~J} / \mathrm{mol} \mathrm{K}$ ) and $\mathrm{T}$ is the temperature (Kelvin). $\Delta \mathrm{H}^{\circ}$ and $\Delta \mathrm{S}^{\circ}$ parameters aree calculated from the slope and intercept of the plot ln $\mathrm{K}_{\mathrm{e}} \mathrm{vs}$. $1 / \mathrm{T}$.

\subsection{Effect of contact time on MB}

\section{Results and discussion}

Contact time is one of the physical parameters used economically for the design of wastewater treatment plants [26]. Fig. 1 shows that the removal of dye from the solutions is rapid in the beginning period and that the velocity near the reach of the balance decreases. At the beginning, the surface of the adsorption process is large, so the adsorption to this surface is fast. The equilibrium time in dye adsorption was determined to be $140 \mathrm{~min}$.

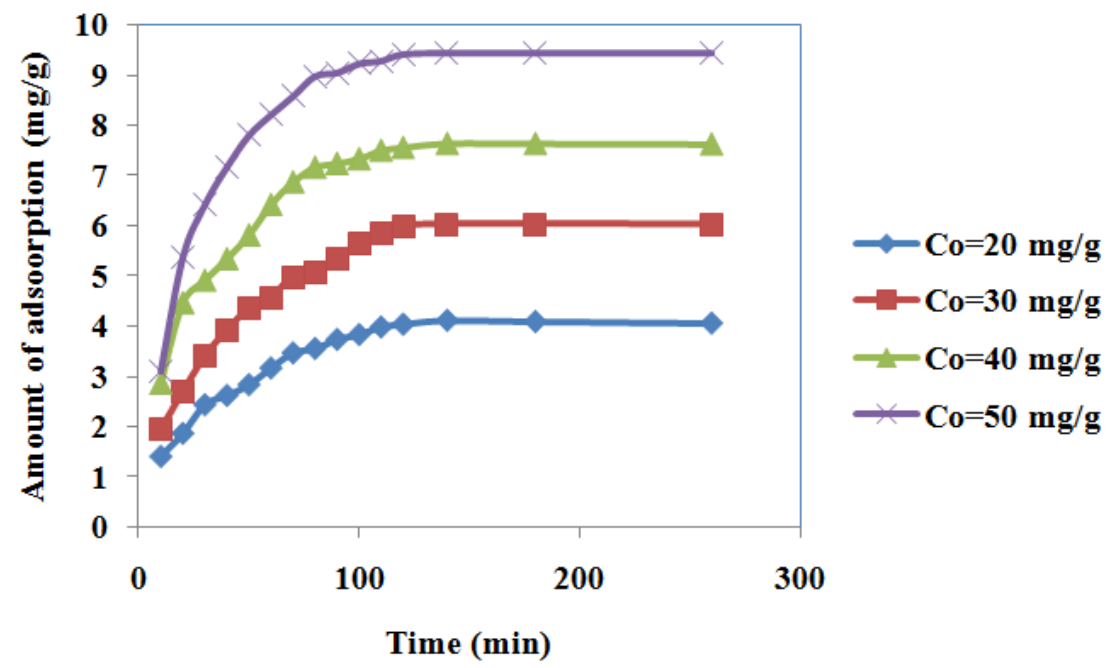

Fig. 1. Effect of contact time and initial dye concentration on dye removal onto PSCFS (natural initial pH, at $318 \mathrm{~K}$, agitation speed $150 \mathrm{rpm}$ ).

\subsection{Effect of initial dye concentrations}

Figure 2 shows that the increase in the initial dye concentration caused the increase in adsorption capacity. As the initial dye concentration increases from 20 to $50 \mathrm{mg} / \mathrm{L}$, the adsorption capacity of dye onto PSCFS from 16.43 to $37.80 \mathrm{mg} / \mathrm{g}$. These data indicate that the initial dye concentration plays an important role in the dye adsorption capacity. However, as shown in Figure 2, the percent removal of dye decreased from 82.15 to $75.59 \%$ on increasing the initial dye concentration from 20 to $50 \mathrm{mg} / \mathrm{L}$. As seen from the figure, the amount of adsorbed dye increases and the percentage of adsorption decreases with the initial dye concentration increases. This indicates that the initial dye concentration provides a driving force to overcome the resistance to dye transfer between the solid phase and the water phase. The increase in initial concentration increases the interaction between adsorbent and dye. Therefore, an increase in initial dye concentration leads to increase in 
the adsorption amount of dye. As can be seen from the experimental data obtained, the adsorption of MB on PSCFS contain three stages; initially fast adsorption, followed by slower adsorption and eventually no adsorption. Similar types of results are reported by various researchers for methylene blue adsorption on sawdust,rice husk, spend tea leaves [27], on seed watermelon pulp [28], on corn husk [29], on sun flower seed hull [30], on raw olive pomace [31] and on maize silk powder [32].

\subsection{Effect of temperature on MB dye adsorption}

The effect of temperature is an important physical parameter since it changes the adsorption capacity of the adsorbent. To study the effect of temperature on the adsorption of MB dye adsorption onto PSCFS, the experiments were carried out at temperatures of 25,35 and $45^{\circ} \mathrm{C}$. Figure 3 shows the effect of temperature on the adsorption of by MB onto PSCFS. As you can see, the amount of adsorbed dye and the percentage of adsorption onto PSCFS were found to increase with increasing temperature. This shows that surface activity increases at higher temperatures and adsorption is endothermic.

\subsection{Thermodynamic parameters}

Thermodynamic parameters have been investigated to determine whether the adsorption phenomenon is favorable or not. $\Delta \mathrm{G}^{\mathrm{o}}, \Delta \mathrm{H}^{\mathrm{o}}$, and $\Delta \mathrm{S}^{\mathrm{o}}$ were obtained from the experimental studies at different temperatures of 298, 308 and $318 \mathrm{~K}$ by the applying of Eqs. 8, 9 and 10 and plot which is not shown here. All thermodynamic parameters are tabulated in Table 1 . The $\Delta \mathrm{G}^{\mathrm{o}}$ values change from -2.4334 to -3.7478 while the temperature varies from 298 to 318 . These negative values indicete that dye adsorption reaction is spontaneous in nature at all the studied temperatures. The increase in $\Delta \mathrm{G}^{0}$ values with increasing temperature is an indication that $\mathrm{MB}$ adsorption on PSCFS is more favorable. The positive $\Delta \mathrm{H}^{\circ}$ value indicates that the reaction is endothermic and consumes energy in the adsorption process. The positive value of $\Delta \mathrm{S}^{\mathrm{o}}$ indicated increased randomness at the solid-solute interface during adsorption.

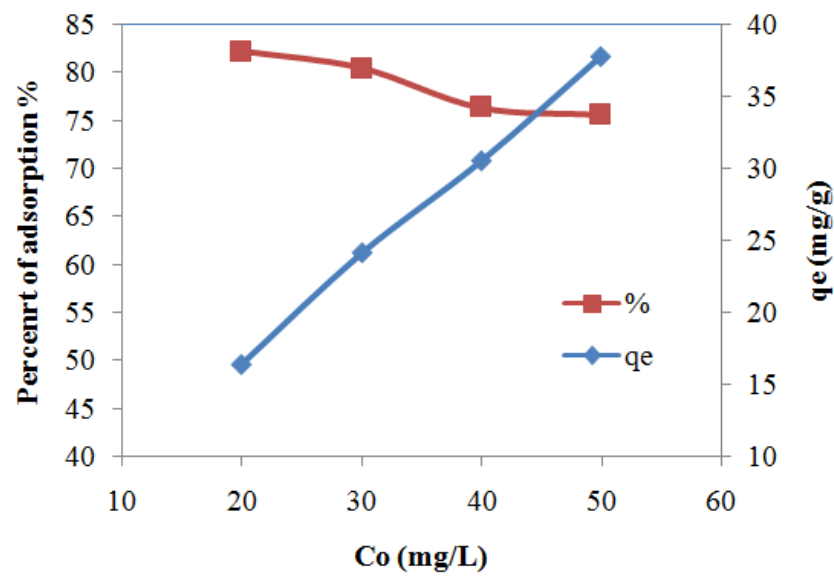

Fig. 2. Effect of initial MB dye concentration on the adsorption of MB onto PSCFS (volume of dye solution 1 $\mathrm{L}$, temperature $45^{\circ} \mathrm{C}$, PSCFS dosage $4 \mathrm{~g}$, natural initial $\mathrm{pH}$, agitation speed $150 \mathrm{rpm}$ ).

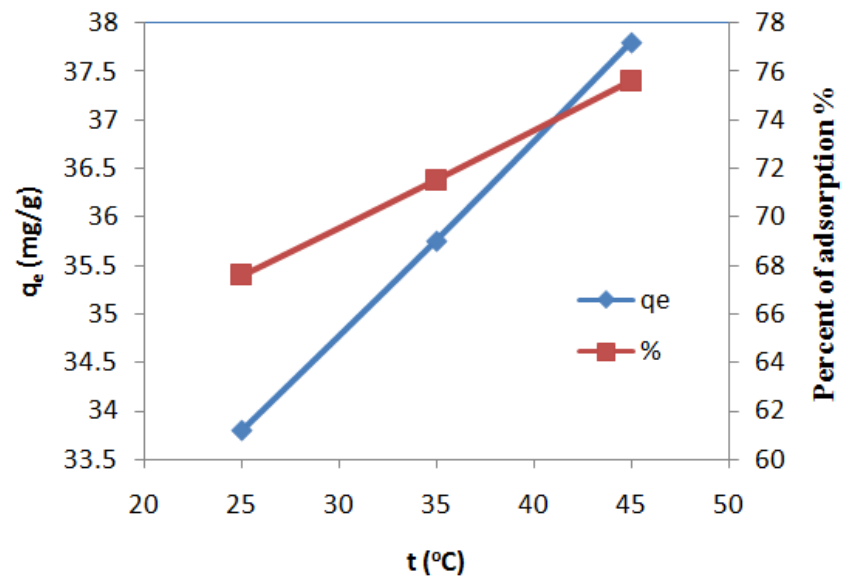

Fig. 3. Effect of temperature on the adsorption of MB onto PSCFS (volume of dye solution $1 \mathrm{~L}$, initial dye concentration $50 \mathrm{mg} / \mathrm{L}$, PSCFS dosage $4 \mathrm{~g}$, natural initial $\mathrm{pH}$, agitation speed $150 \mathrm{rpm}$ ). 
Kinetics And Thermodynamic Studies Of Adsorption Of Methylene Blue From Aqueous Solutio...

Table 1 Thermodynamic parameters for adsorption of MB onto PSCFS at different temperatures and

concentrations

\begin{tabular}{|l|l|l|l|}
\hline Temperature (K) & $-\Delta \mathbf{G}^{\mathbf{0}}(\mathbf{k J} / \mathbf{m o l})$ & $\Delta \mathbf{S}^{\mathbf{0}}(\mathbf{J} / \mathbf{m o l} \mathbf{~ K})$ & $\Delta \mathbf{H}^{\mathbf{0}}(\mathbf{k J} / \mathbf{m o l})$ \\
\hline 298 & 2.4334 & 66.9117 & 17.5301 \\
308 & 3.0787 & & \\
318 & 3.7478 & & \\
\hline
\end{tabular}

\subsection{Adsorption kinetics}

The study of kinetics in adsorption treatment from water solutions is important because it gives important information about the reaction and the mechanism of the adsorption process. In this study, the pseudo-first-order, pseudo-second-order, intra-particle diffusion, Elovich, Bangham and Avrami kinetics model was tested for the adsorption of MB into PSCFS. The best fit model was chosen based on linear regression coefficient of correlation coefficients $\mathrm{R}^{2}$ values. These models have been investigated according to experimental data at different temperatures and concentrations. The linear graphs for these models are shown for only $298 \mathrm{~K}$ temperature. All kinetic parameters obtained from fitting model plots with experimental data under various conditions are presented in Tables 2, 3 and 4.

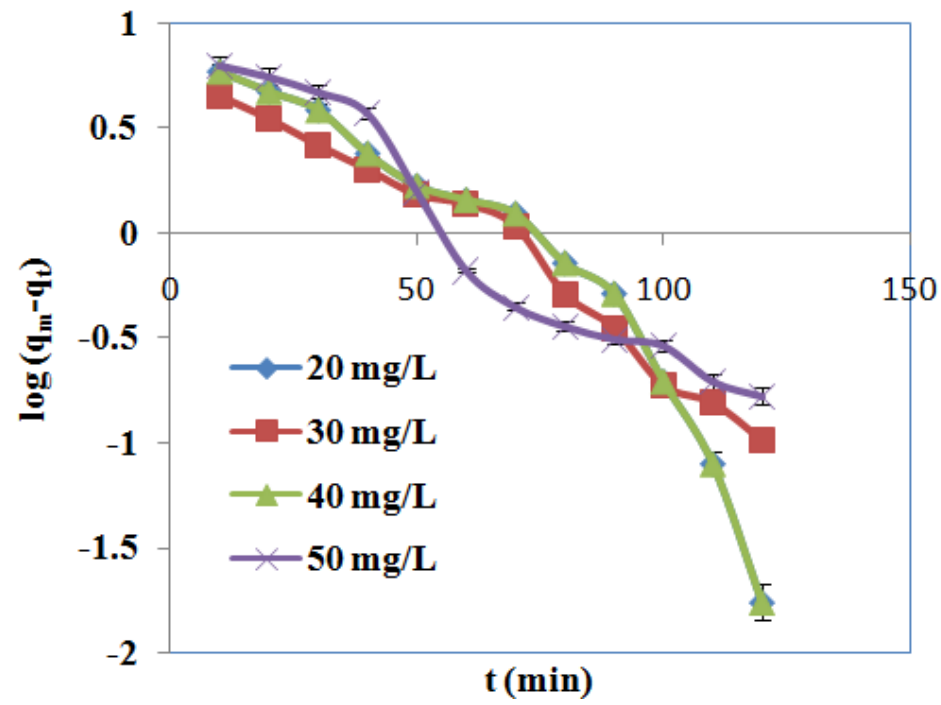

Fig.4. Pseudo-first-order kinetic model on different initial dye concentration at $298 \mathrm{~K}$.

The $\mathrm{R}^{2}$ values obtained for the pseudo-first-order kinetic model were lower than that of the pseudosecond-order kinetic model and the experimental $\mathrm{q}_{\mathrm{e}}$ values did not agree with the calculated values obtained from the linear plots (Table 2,3 and 4). This indicates that the adsorption of MB onto PSCFS does not follow pseudo-first-order kinetics. The similar results were found for the adsorption of MB ions on various adsorbents by several authors $[33,34]$.

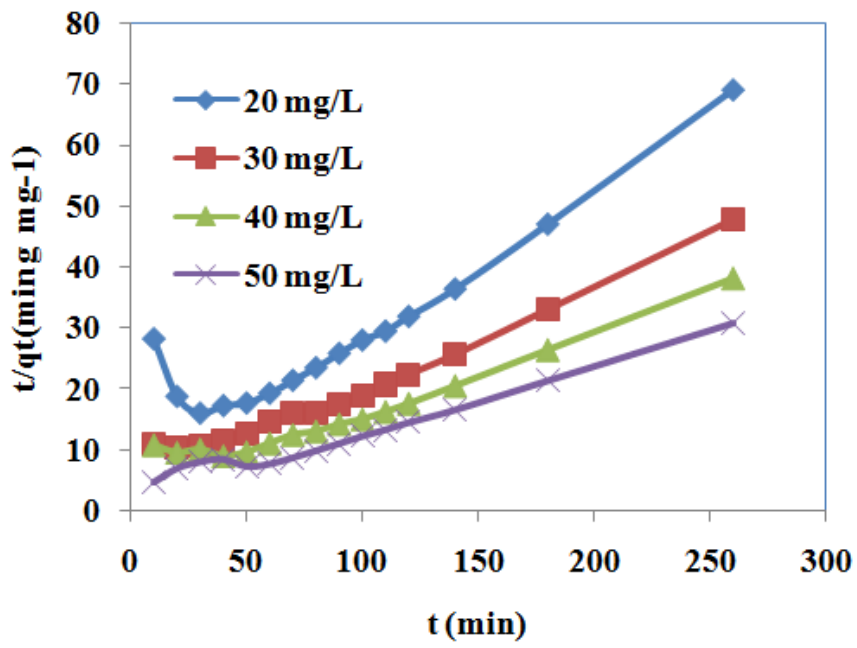

Fig.5. Pseudo-second-order kinetic model on different initial dye concentration at $298 \mathrm{~K}$. 
When an evaluation is made taking into consideration the temperatures and concentrations used for the kinetic analyzes, it is found that the maximum average $\mathrm{k}_{2}$ value is $6.9475 \times 10^{-3} \mathrm{~g} / \mathrm{mg} \mathrm{min}$ at $318 \mathrm{~K}$. It was determined that the maximum initial velocity value was $0.6623 \mathrm{mg} / \mathrm{g}$ min at a concentration of $318 \mathrm{~K} 50 \mathrm{mg} /$ L. When theoretically and experimentally calculated adsorption capacities are compared, it is determined that the values obtained at $318 \mathrm{~K}$ are closer to each other. When the correlation coefficients are examined, it is observed that the most suitable value is in this model. This shows that it is more appropriate to explain the obtained data with a pseudo-second-order kinetic model.

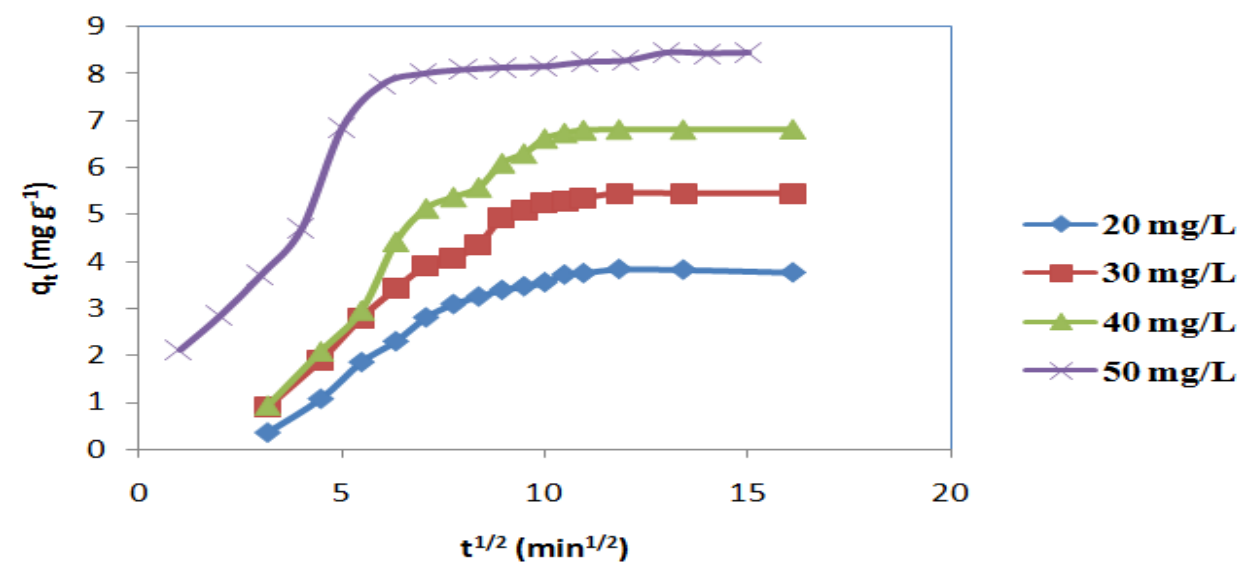

Fig.6. Intraparticle diffusion kinetic model on different initial dye concentration at $298 \mathrm{~K}$.

When Figure 6 is examined, it is observed that there are three phases in MB adsorption. It can be interpreted that the dye molecules are sorption to the outer surface of the adsorbent, in the first stage when the amount of adsorbed material increases rapidly, diffuse in the pores of the adsorbent in the second stage where the adsorption rate slows down and in the third stage the adsorption phenomenon is balanced. When the data related to intraparticle diffusion in Tables 2, 3 and 4 were examined, it was observed that $\mathrm{R}^{2}$ values were small. From tables data, with increasing temperature and concentration, it is observed that $\mathrm{C}$ values increased and $\mathrm{Kp}$ values decreased. The linear plots do not pass through the origin which indicates that intraparticle diffusion is not the only rate controlling step [35].

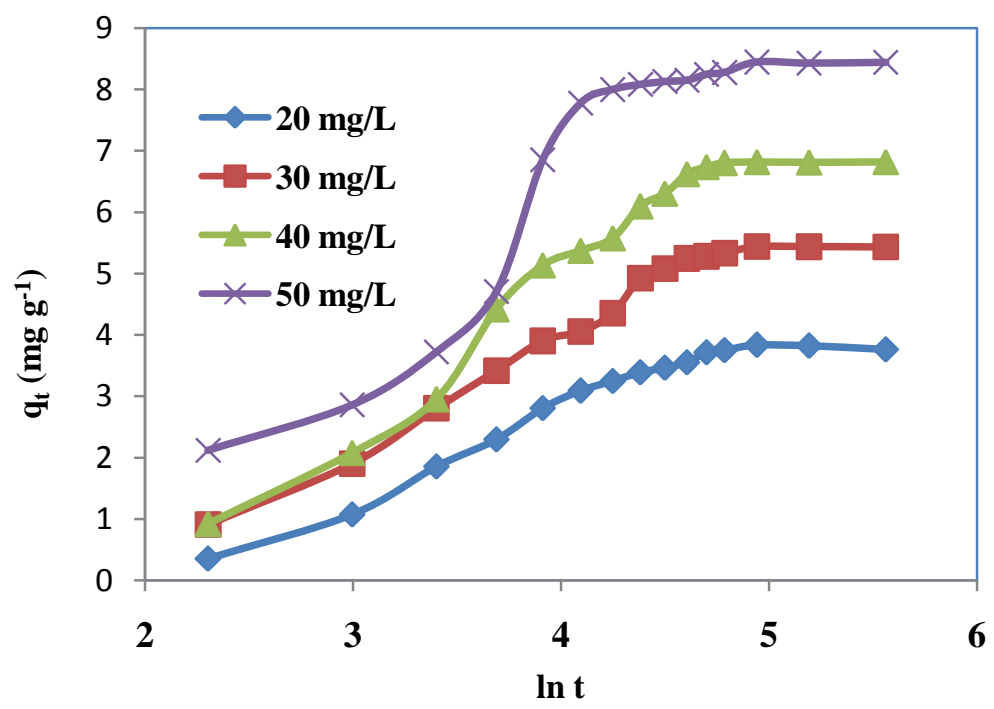

Fig.7. Elovich kinetic model on different initial dye concentration at $298 \mathrm{~K}$.

The Elovich equation is a very common model for describing chemisorption processes. The constants of Elovich equation and the correlation coefficient are given in tables 2, 3 and 4. It is observed that the values of $\mathrm{a}_{\mathrm{E}}\left(\mathrm{mg} \mathrm{g}^{-1} \mathrm{~min}^{-1}\right)$ increase with the increase of initial concentration and temperature in the range of studied 
values. The values of the regression coefficient $\left(\mathrm{R}^{2}=0.8462-0.9540\right)$ of the Elovich kinetic model suggest that kinetic data did not follow the Elovich model.

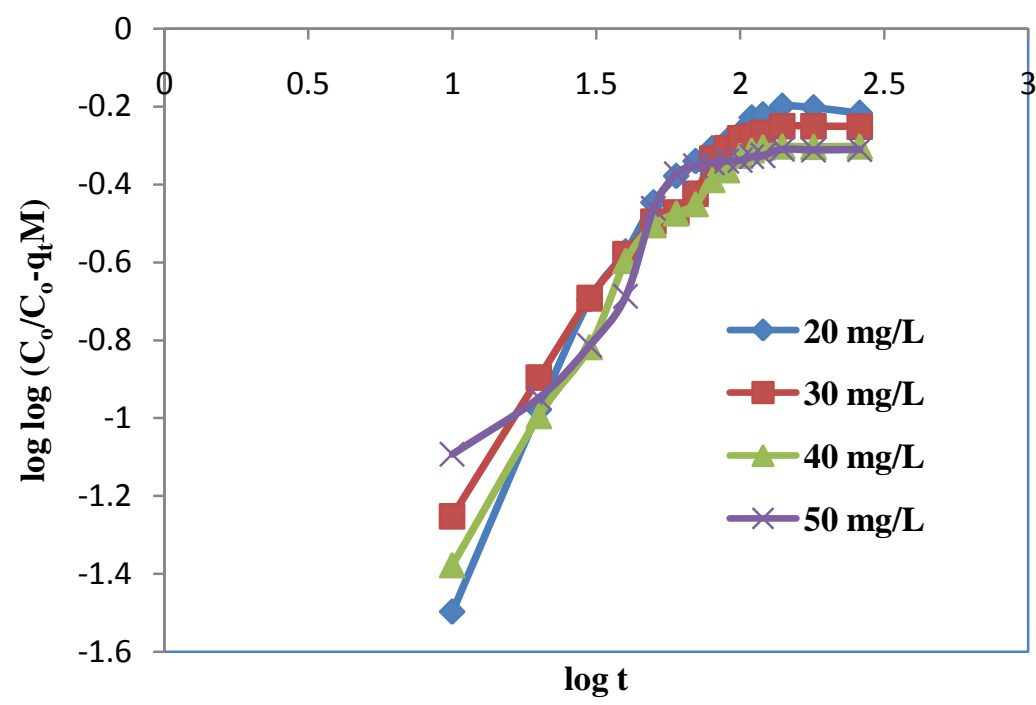

Fig.8. Bangham kinetic model on different initial dye concentration at $298 \mathrm{~K}$.

Tables 2, 3 and 4 are given the kinetic constants obtained from the Bangham equation. When the tables are examined, it is seen that $b$ value decreases with increasing temperature. It is observed that $k_{B}$ value increases with increasing temperature. It is seen that the correlation coefficient obtained from the tables Elovich model is larger than that obtained by Bangham model. These results confirm that the adsorption rate is not controlled only by the pore diffusion. The graphs of the kinetic model of Avrami at various concentrations and $298 \mathrm{~K}$ are shown in fig.9. The kinetic data calculated from the Avrami equation are given in Tables 2, 3 and 4. From the tables, it seems that the calculated Avrami constants depend on the temperature. From these constants, while the values of $\mathrm{n}_{\mathrm{Av}}$ decreases with temperature, the values of $\mathrm{k}_{\mathrm{Av}}$ increase with temperature. When the temperature rises, the increase in $\mathrm{k}_{\mathrm{Av}}$ value is indicative of increased the reaction speed with temperature.

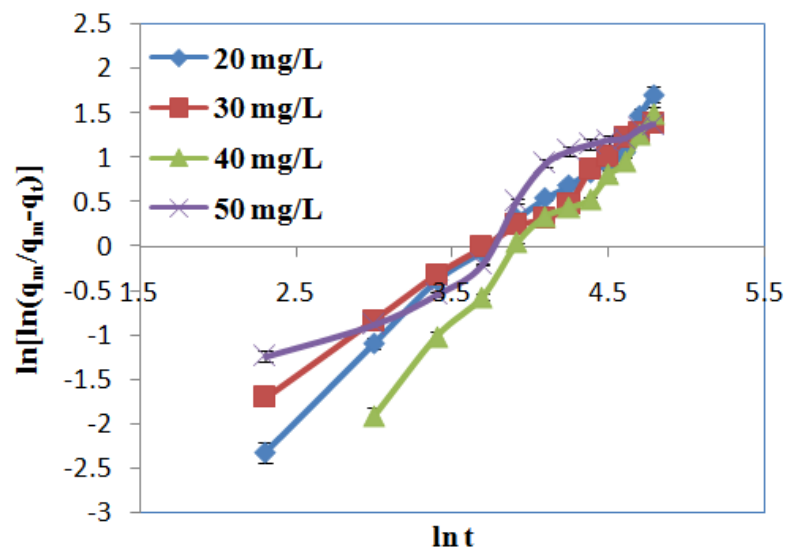

Fig.9. Avrami kinetic model on different initial dye concentration at $298 \mathrm{~K}$. 
Table 2 Kinetic models for the adsorption of MB adsorption onto PSCFS at $298 \mathrm{~K}$

\begin{tabular}{|c|c|c|c|c|c|}
\hline \multirow[t]{2}{*}{ Kinetic models } & \multirow[t]{2}{*}{ Parameters } & \multicolumn{4}{|c|}{ Adsorbent matter } \\
\hline & & $20 \mathrm{mg} / \mathrm{L}$ & $30 \mathrm{mg} / \mathrm{L}$ & $40 \mathrm{mg} / \mathrm{L}$ & $50 \mathrm{mg} / \mathrm{L}$ \\
\hline \multirow[t]{3}{*}{ Pseudo-first order } & $\mathrm{q}_{\mathrm{e} \text { calc }}(\mathrm{mg} / \mathrm{g})$ & 7.8001 & 8.1452 & 16.2855 & 10.2920 \\
\hline & $\mathrm{k}_{1}\left(\min ^{-1}\right)$ & $4.31 \times 10^{-2}$ & $3.52 \times 10^{-2}$ & $4.61 \times 10^{-2}$ & $3.73 \times 10^{-2}$ \\
\hline & $\mathrm{R}^{2}$ & 0.9065 & 0.9726 & 0.8948 & 0.9417 \\
\hline \multirow[t]{5}{*}{ Pseudo-second order } & $\mathrm{q}_{\mathrm{e} \exp }(\mathrm{mg} / \mathrm{g})$ & 3.7625 & 5.4350 & 6.8200 & 8.4443 \\
\hline & $\mathrm{q}_{\mathrm{e} \text { calc }}(\mathrm{mg} / \mathrm{g})$ & 5.1256 & 9.5147 & 8.7260 & 10.0300 \\
\hline & $\mathrm{k}_{2}(\mathrm{~g} / \mathrm{mg} \min )$ & $3.43 \times 10^{-3}$ & $1.92 \times 10^{-3}$ & $2.50 \times 10^{-3}$ & $3.23 \times 10^{-3}$ \\
\hline & $\mathrm{h}(\mathrm{mg} / \mathrm{g} \min )$ & 0.0901 & 0.1734 & 0.1900 & 0.3248 \\
\hline & $\mathrm{R}^{2}$ & 0.8604 & 0.9722 & 0.9407 & 0.9660 \\
\hline \multirow[t]{3}{*}{ Intraparticle diffusion } & $\mathrm{k}_{\mathrm{p}}(\mathrm{mg} / \mathrm{g} \min )$ & 0.2713 & 0.3652 & 0.4809 & 0.5451 \\
\hline & $\mathrm{C}(\mathrm{mg} / \mathrm{g})$ & 0.5121 & 0.9748 & 1.0057 & 1.9515 \\
\hline & $\mathrm{R}^{2}$ & 0.7478 & 0.7808 & 0.7557 & 0.6889 \\
\hline \multirow[t]{3}{*}{ Elovich equation } & $\mathrm{b}_{\mathrm{E}}(\mathrm{g} / \mathrm{mg})$ & 0.8313 & 0.6255 & 0.4718 & 0.4134 \\
\hline & $a_{E}(m g / g$ min $)$ & 0.2023 & 0.3317 & 0.3789 & 0.5944 \\
\hline & $\mathrm{R}^{2}$ & 0.9170 & 0.9331 & 0.9155 & 0.8462 \\
\hline \multirow[t]{3}{*}{ Bangham } & $\mathrm{b}$ & 0.8990 & 0.7328 & 0.7866 & 0.6487 \\
\hline & $\mathrm{k}_{\mathrm{B}}$ & $4.53 \times 10^{-3}$ & $8.88 \times 10^{-3}$ & $6.26 \times 10^{-3}$ & $1.21 \times 10^{-2}$ \\
\hline & $\mathrm{R}^{2}$ & 0.8593 & 0.9010 & 0.8766 & 0.8476 \\
\hline \multirow[t]{3}{*}{ Avrami } & $\mathrm{n}_{\mathrm{Av}}$ & 1.4964 & 1.2287 & 1.4109 & 1.2177 \\
\hline & $\mathrm{k}_{\mathrm{Av}}$ & $2.32 \times 10^{-2}$ & $2.46 \times 10^{-2}$ & $2.42 \times 10^{-2}$ & $2.83 \times 10^{-2}$ \\
\hline & $\mathrm{R}^{2}$ & 0.9878 & 0.9911 & 0.9830 & 0.9425 \\
\hline
\end{tabular}

Table 3 Kinetic models for the adsorption of MB adsorption onto PSCFS at $308 \mathrm{~K}$

\begin{tabular}{|c|c|c|c|c|c|}
\hline \multirow[t]{2}{*}{ Kinetic models } & \multirow[t]{2}{*}{ Parameters } & \multicolumn{4}{|c|}{ Adsorbent matter } \\
\hline & & $20 \mathrm{mg} / \mathrm{L}$ & $30 \mathrm{mg} / \mathrm{L}$ & $40 \mathrm{mg} / \mathrm{L}$ & $50 \mathrm{mg} / \mathrm{L}$ \\
\hline \multirow[t]{3}{*}{ Pseudo-first order } & $\mathrm{q}_{\mathrm{e} \text { calc }}(\mathrm{mg} / \mathrm{g})$ & 5.3432 & 8.3157 & 7.5579 & 11.1661 \\
\hline & $\mathrm{k}_{1}\left(\min ^{-1}\right)$ & $2.49 \times 10^{-2}$ & $3.32 \times 10^{-2}$ & $2.21 \times 10^{-2}$ & $3.32 \times 10^{-2}$ \\
\hline & $\mathrm{R}^{2}$ & 0.8849 & 0.9450 & 0.9575 & 0.9695 \\
\hline \multirow[t]{5}{*}{ Pseudo-second order } & $\mathrm{q}_{\mathrm{e} \exp }(\mathrm{mg} / \mathrm{g})$ & 3.9975 & 5.8188 & 7.2180 & 8.9358 \\
\hline & $\mathrm{q}_{\mathrm{e} \text { calc }}(\mathrm{mg} / \mathrm{g})$ & 5.3734 & 6.9252 & 8.6356 & 10.1729 \\
\hline & $\mathrm{k}_{2}(\mathrm{~g} / \mathrm{mg} \min )$ & $2.93 \times 10^{-3}$ & $4.27 \times 10^{-3}$ & $2.94 \times 10^{-3}$ & $3.83 \times 10^{-3}$ \\
\hline & $\mathrm{h}(\mathrm{mg} / \mathrm{g} \min )$ & 0.0847 & 0.2050 & 0.2194 & 0.3966 \\
\hline & $\mathrm{R}^{2}$ & 0.9506 & 0.9871 & 0.9884 & 0.9917 \\
\hline \multirow[t]{3}{*}{ Intraparticle diffusion } & $\mathrm{k}_{\mathrm{p}}(\mathrm{mg} / \mathrm{g} \min )$ & 0.2926 & 0.3740 & 0.4575 & 0.5155 \\
\hline & $\mathrm{C}(\mathrm{mg} / \mathrm{g})$ & 0.2361 & 1.1932 & 1.2850 & 2.5585 \\
\hline & $\mathrm{R}^{2}$ & 0.8651 & 0.8136 & 0.8843 & 0.7971 \\
\hline \multirow[t]{3}{*}{ Elovich equation } & $\mathrm{b}_{\mathrm{E}}(\mathrm{g} / \mathrm{mg})$ & 0.8304 & 0.6200 & 0.5255 & 0.4479 \\
\hline & $a_{E}(\mathrm{mg} / g$ min $)$ & 0.1882 & 0.3931 & 0.4693 & 0.8096 \\
\hline & $\mathrm{R}^{2}$ & 0.9135 & 0.9434 & 0.9540 & 0.9324 \\
\hline \multirow[t]{3}{*}{ Bangham } & $\mathrm{b}$ & 0.7647 & 0.6779 & 0.5995 & 0.5553 \\
\hline & $\mathrm{k}_{\mathrm{B}}$ & $8.01 \times 10^{-3}$ & $1.28 \times 10^{-2}$ & $1.48 \times 10^{-2}$ & $1.98 \times 10^{-2}$ \\
\hline & $\mathrm{R}^{2}$ & 0.9407 & 0.9375 & 0.9614 & 0.9263 \\
\hline \multirow[t]{3}{*}{ Avrami } & $\mathrm{n}_{\mathrm{Av}}$ & 0.9681 & 1.0745 & 0.8523 & 0.9820 \\
\hline & $\mathrm{k}_{\mathrm{Av}}$ & $1.90 \times 10^{-2}$ & $2.56 \times 10^{-2}$ & $2.27 \times 10^{-2}$ & $2.94 \times 10^{-2}$ \\
\hline & $\mathrm{R}^{2}$ & 0.9123 & 0.9746 & 0.9546 & 0.9657 \\
\hline
\end{tabular}

When comparing $\mathrm{R}^{2}$ values obtained from kinetic models, the results reveal that kinetic models fitted in the order: pseudo-second order $>$ Avrami $>$ pseudo-first order $>$ Elovich $>$ Bangham $>$ intraparticle diffusion. This demonstrates that the pseudo-second-order kinetic model better describes the adsorption process. Moreover, the $\mathrm{q}_{\mathrm{e}}$ values obtained with this model are closer to the values obtained from the experimental data. 
Table 4 Kinetic models for the adsorption of MB adsorption onto PSCFS at $318 \mathrm{~K}$

\begin{tabular}{|c|c|c|c|c|c|}
\hline \multirow[t]{2}{*}{ Kinetic models } & \multirow[t]{2}{*}{ Parameters } & \multicolumn{4}{|c|}{ Adsorbent matter } \\
\hline & & $20 \mathrm{mg} / \mathrm{L}$ & $30 \mathrm{mg} / \mathrm{L}$ & $40 \mathrm{mg} / \mathrm{L}$ & $50 \mathrm{mg} / \mathrm{L}$ \\
\hline \multirow[t]{3}{*}{ Pseudo-first order } & $\mathrm{q}_{\mathrm{e} \mathrm{calc}}(\mathrm{mg} / \mathrm{g})$ & 6.2001 & 8.7640 & 8.6000 & 12.3197 \\
\hline & $\mathrm{k}_{1}\left(\min ^{-1}\right)$ & $3.80 \times 10^{-2}$ & $3.52 \times 10^{-2}$ & $3.66 \times 10^{-2}$ & $4.26 \times 10^{-2}$ \\
\hline & $\mathrm{R}^{2}$ & 0.8798 & 0.8502 & 0.9684 & 0.9350 \\
\hline \multirow[t]{5}{*}{ Pseudo-second order } & $\mathrm{q}_{\mathrm{e} \exp }(\mathrm{mg} / \mathrm{g})$ & 4.0523 & 6.0295 & 7.6125 & 9.4475 \\
\hline & $\mathrm{q}_{\mathrm{e} \text { calc }}(\mathrm{mg} / \mathrm{g})$ & 4.6019 & 6.8776 & 8.3403 & 10.2987 \\
\hline & $\mathrm{k}_{2}(\mathrm{~g} / \mathrm{mg} \min )$ & $8.96 \times 10^{-3}$ & $5.53 \times 10^{-3}$ & $7.06 \times 10^{-3}$ & $6.24 \times 10^{-3}$ \\
\hline & $\mathrm{h}(\mathrm{mg} / \mathrm{g} \min )$ & 0.1897 & 0.2617 & 0.4908 & 0.6623 \\
\hline & $\mathrm{R}^{2}$ & 0.9930 & 0.9939 & 0.9963 & 0.9963 \\
\hline \multirow[t]{3}{*}{ Intraparticle diffusion } & $\mathrm{k}_{\mathrm{p}}\left(\mathrm{mg} / \mathrm{g} \min ^{0.5}\right)$ & 0.2270 & 0.3437 & 0.3691 & 0.4558 \\
\hline & $\mathrm{C}(\mathrm{mg} / \mathrm{g})$ & 1.2525 & 1.7344 & 3.1296 & 3.9978 \\
\hline & $\mathrm{R}^{2}$ & 0.8188 & 0.8318 & 0.7704 & 0.7139 \\
\hline \multirow[t]{3}{*}{ Elovich equation } & $\mathrm{b}_{\mathrm{E}}(\mathrm{g} / \mathrm{mg})$ & 1.0254 & 0.6791 & 0.6169 & 0.4872 \\
\hline & $a_{E}(m g / g$ min $)$ & 0.4131 & 0.5637 & 1.2521 & 1.5340 \\
\hline & $\mathrm{R}^{2}$ & 0.9421 & 0.9522 & 0.9266 & 0.9027 \\
\hline \multirow[t]{3}{*}{ Bangham } & $\mathrm{b}$ & 0.5765 & 0.5857 & 0.4746 & 0.4945 \\
\hline & $\mathrm{k}_{\mathrm{B}}$ & $2.33 \times 10^{-2}$ & $2.13 \times 10^{-2}$ & $3.44 \times 10^{-2}$ & $3.20 \times 10^{-2}$ \\
\hline & $\mathrm{R}^{2}$ & 0.9456 & 0.9533 & 0.9202 & 0.8814 \\
\hline \multirow[t]{3}{*}{ Avrami } & $\mathrm{n}_{\mathrm{Av}}$ & 0.9547 & 0.9410 & 0.8996 & 0.9949 \\
\hline & $\mathrm{k}_{\mathrm{Av}}$ & $3.11 \times 10^{-2}$ & $2.93 \times 10^{-2}$ & $3.77 \times 10^{-2}$ & $3.79 \times 10^{-2}$ \\
\hline & $\mathrm{R}^{2}$ & 0.9302 & 0.9315 & 0.9650 & 0.9809 \\
\hline
\end{tabular}

\section{Conclusions}

1-The adsorption of dye MB on PSCSF was examined at different experimental conditions. The results show that adsorption increases with increase in temperature, initial concentration and contact time.

2-The maximum removal of dye at $318 \mathrm{~K}$ was found $\% 82$.

3 -Kinetic study shows the adsorption reaction follows pseudo-second order kinetic model (average $\mathrm{R}^{2}$ value 0.9697).

4-The negative value of change in $\Delta \mathrm{G}^{\mathrm{o}}$ (Gibb's free energy) implied that the reaction is spontaneous in nature, the values are more negative with temperature that adsortion is favored with increased in temperature for the studied adsorbent.

5-Adsorption is favored at high temperature fort he studied adsorbent which is also confirmed by the pozitive values of enthalpy change.

\section{References}

[1]. V. Gupta, A.I. Suhas, V. Saini, (2004). Removal of rhodamine B, fast green, and methylene blue from wastewater using red mud, an aluminum industry waste, Industrial and Engineering Chemistry Research, 43(7), 2004, 1740-1747.

[2]. J.O. Hao, H. Kim, P.C.Chiang, Decolourization of wastewater. Critical Review in Environmental Science and Technology, 30(4), 2000, 449-505.

[3]. T.K. Sen, S. Afroze, H. Ang, Equilibrium, kinetics and mechanism of removal of methylene blue from aqueous solution by adsorption onto pine cone biomass of Pinus radiata, Water, Air and Soil Pollution, 218(1), 2011, 499-515.

[4]. M. M. Abd EI-Latif, A.M. Ibrahim, M.F. EI-Kady, Adsorption equilibrium, kinetics and thermodynamics of methylene blue from aqueous solutions using biopolymer oak sawdust composite, Journal of American Science 6(6), 2010, 267-283

[5]. S. Dawood, T.K. Sen, Removal of anionic dye Congo red from aqueous solution by raw pine and acid-treated pine cone powder as adsorbent: equilibrium, thermodynamic, kinetics, mechanism and process design. Water Research, 46(6), 2012, $1933-1946$.

[6]. N. M. Mahmoode, B. Hagali, M. Ararm, C. Lan, Adsorption of textile dyes on pine cone from collared wastewater: kinetics, equilibrium and thermodynamic studies. Desalination, 268, 2011, 117-125.

[7]. K.G. Akpomie, F.A. Dawodu, K.O. Adebowale, Mechanism on the sorption of heavy metals from binary solution by a low cost montmorillonite and its desorption potential, Alexandria Engineering Journal, 54, 2015, 757-767.

[8]. M. T. Yagub, T.K. Sen, S. Afroze, H.M. Ang, Dye and its removal from aqueous solution by adsorption: a review, Advances in Colloid and Interface Science, 209, 2014, 172-184.

[9]. A. Ebrahimi, M. Arami,H. Bahrami, E. Pajootan, Fish Bone as a low-cost adsorbent for dye removal from wastewater: response surface methodology and classical method, Environmental Modeling and Assessment, 18 (6), 2013, 1-10.

[10]. G. Akkaya, F. Güzel, Application of some domestic wastes as new low-cost biosorbents for removal of methylene blue: kinetic and equilibrium studies, Chemical Engineering Communications 201(4), 2014, 557-578.

[11]. A. Ahmad, M. Rafatullah, O. Sulaiman, M. Ibrahim, R. Hashim, Scavenging behaviour of meranti sawdust in the removal of methylene blue from aqueous solution,. Journal of Hazardous Materials, 170(1), 2009, 357-365. 
[12]. L.W. Low, T.T. Teng, M. Rafatullah, N. Morad, B. Azahari, Adsorption studies of methylene blue and malachite green from aqueous solutions by pretreated lignocellulosic materials, Separation Science and Technology, 48(11), 2013, 1688-1698.

[13]. Z. M. Hussin, N. Talib, N.M. Hussin, M.A. Hanafiah, W.K. Khalir, Methylene blue adsorption onto NaOH modified durian leaf powder: isotherm and kinetic studies, American Journal of Environmental Engineering 5 (3A), 2015, 38-43.

[14]. H. Saygili, G. Akkaya Saygili, F. Güzel, Using grape pulp as a new alternative biosorbent for removal of a model basic dye, AsiaPacific Journal Chemical Engineering, 9(2), 2014, 214-225.

[15]. [M. Vakili, M. Rafatullah, B. Salamatinia, A.Z. Abdullah. M.H. Ibrahim, K.B. Tan, Z. Gholami, P. Amouzgar, Application of chitosan and its derivatives as adsorbents for dye removal from water and wastewater: a review, Carbohydrate Polymer, 113, 2014, 115-130.

[16]. M. S. Sajab, C.H. Chia, S. Zakaria, S.M. Jani, M.K. Ayob, K.L. Chee, P.S. Khiew, W.S. Chiu, Citric acid modified kenaf core fibres for removal of methylene blue from aqueous solution, Bioresource Technology, 102 (15), 2011, 7237-7243.

[17]. M. Dogan, H. Abak, M. Alkan, Adsorption of methylene blue onto hazelnut shell: Kinetics, mechanism and activation parameters, Journal of Hazardous Materials, 164 (1), 2009, 172-181.

[18]. V. Ponnusami, V. Gunasekar, S. N. Srivastava, Kinetics of Methylene blue removal from aqueous solution using gulmohar (Delonix regia) plant leaf powder: multivariate regression analysis, Journal of Hazardous Materials, 169 (1-3), 2009,119-127.

[19]. Y. S. Ho, G. McKay, Sorption of dye from aqueous solution by peat, Chemical Engineering Journal, 70 (2), 1998, 115-124.

[20]. M. Arami, N.Y. Limaee, N.M. Mahmoodia, Evaluation of the adsorption kinetics and equilibrium for the potential removal of acid dyes using a biosorbent, Chemical Engineering Journal, 139 (1), 2008, 2-10.

[21]. D. L. Sparks, Kinetics of soil chemical processes (Academic Press, San Diego, California, 1989).

[22]. J. Zhang, R. Stanforth, Slow adsorption reaction between aresenic species and geohite $(\mathrm{\alpha}-\mathrm{FeOOH})$ : diffusion or heteregenous surface reaction control. Langmuir, 21(7), 2005, 2895-2901.

[23]. I. D. Mall, V.C. Srivastava, N. K. Agarwal, Removal of Orange-G and methyl violet dyes by adsorption on to bagasse fly ashkinetic study and equilibrium isotherm analyses, Dyes and Pigments, 69 (3), 2006, 210-223.

[24]. M. A. Malana, R. B. Qureshi, M.N. Ashiq, Adsorption studies of arsenic on nano aluminium doped manganese copper ferrite polymer (MA, VA, AA) composite: Kinetics and mechanism, Chemical Engineering Journal 172 (2-3), 2011, 721-727.

[25]. E.C.N. Lopes, F.S.C. dos Anjos, E.F.S. Vieira, A.R. Cestari, An alternative Avrami equation to evaluate kinetic parameters of the interaction of $\mathrm{Hg}$ (II) with thin chitosan membranes, Journal of Colloid and Interface Science 263 (2), 2003, 542-547.

[26]. P.Saueprasearsit, M. Nuanjaraen, M. Chinlapa, Biosorption of lead $\left(\mathrm{Pb}^{2+}\right)$ by luffa cylindrical fiber, Environmental Research Journal, 4 (1), 2010, 157-166.

[27]. I. H. Dakhil, A comparative study for removal of dyes from textile effluents by low cost adsorbents, Mesopotamia Environmental Journal, A(1-9), 2016, 2410-2598.

[28]. C. Chen, Y. Fu, L. Yu, L. Jun, L. De-qiang, Removal of methylene blue by seed-watermelon pulp-based low-cost adsorbent: Study of adsorption isotherms and kinetic models, Journal of Dispersion Science and Technology, 38(8), 2017, 1142-1146.

[29]. D.S. Malik, C.K. Jain, K.Y. Anuj, R. Kothari, V.V. Pathak, Removal of methylene blue dye in aqueous solution by agricultural waste, International Research Journal of Engineering and Technology, 3(7), 2016, 864-879.

[30]. G. B. Oguntimein, Biosorption of dye from textile wastewater effluent onto alkali treated dried sunflower seed hull and design of a batch adsorbe, Journal of Environmental Chemical Engineering 3(4), 2015, 2647-2661.

[31]. E. Kalıpcl, Removal of methylene blue from aqueous solutions with natural olive pomace modified with ultrasounds and acid, Environment Protection Engineering, 42(3), 2016, 5-17.

[32]. S. M. Miraboutalebi, S.K. Nikouzad, M. Peydayesh, N. Allahgholi, L. Vafajoo, G. McKay, Methylene blue adsorption via maize silk powder: Kinetic, equilibrium, thermodynamic studies and residual error analysis, Process Safety and Environmental Protection, 106, 2017, 191-202.

[33]. Y. Bulut, A. Aydın, A kinetics and thermodynamics study of methylene blue adsorption on wheat shells, Desalination, 194 (1-3), 2006, 259-267.

[34]. D. L. Postai, C. A. Demarchi, F. Zanatta, D.C.C. Melo, C. A. Rodrigues, Adsorption of rhodamine B and methylene blue dyes using waste of seeds of Aleurites Moluccana, a low cost adsorbent, Alexandria Engineering Journal, 155(2) , 2016, 1713-1723.

[35]. B. H. Hameed, (2008). Equilibrium and kinetic studies of methyl violet sorption by agricultural waste, Journal Hazardous Materials, 154 (1-3), 2008, 201-202. 